\title{
Data analysis in Cashless Payment Systems
}

\author{
Alexey Bataev ${ }^{1 *}$, Antonina Glushkova ${ }^{2}$ \\ ${ }^{1}$ Peter the Great St.Petersburg Polytechnic University, Polytechnicheskaya, 29, St.Petersburg, 195251, \\ Russia \\ ${ }^{2}$ Samara University, Moskovskoye shosse 34, Samara, 443086, Russia
}

\begin{abstract}
The use of artificial intelligence in the financial sphere are analyzed in this study. One of the possible areas of using neural network in financial institutions is the system of cashless payments. One of the main problems in introducing innovative projects is to evaluate the efficiency of the implemented information system. In this regard, the construction of an investment model that allows evaluating the implementation and use of artificial intelligence in the cashless payments system of financial institutions is proposed in this article. Based on the constructed model, an analysis is made of the dependence of the effectiveness of the system with artificial intelligence on the size of the client base of a credit organization, while the minimum and maximum possible efficiency parameters of the implemented system are evaluated. Based on a comprehensive analysis, recommendations are given on perspectives of introducing such systems into credit organizations.
\end{abstract}

\section{Introduction}

The modern world is a dynamically changing system in which changes occur at an accelerated pace. Today, the introduction of new technologies takes months, although some time ago it took years.

The introduction of innovative digital technologies led to the beginning of the fourth industrial revolution, the main task of which is to ensure the creation of a "smart economy" that can adapt to the needs and requirements of each individual.

Building a "smart economy" is impossible without introducing artificial intelligence technologies, which are widely used in all areas. The creation of a new type of economy is impossible without the development of innovative production, where one of the promising areas is the introduction of intelligent robotics - robots using neural network technologies, finance, which has become one of the promising areas for using artificial intelligence technologies, for example, the creation of advisory systems on stock markets.

Today, the financial sector develops an innovative economy, introducing the most promising digital technologies in the banking sector. One of the directions of using innovations is the sphere of cashless payments, in which various experiments are carried out, using new advances in the field of information technology that can reduce the amount of

* Corresponding author: bat_a68@mail.ru 
money lost from fraudulent transactions in this area. According to statistics, the annual amount of stolen money in the field of non-cash payments of individuals is about 15-20 billion dollars. While in recent years, regulators of many countries have begun to make higher demands on financial institutions for the responsibility of credit organizations for the safety of clients' funds, which makes banks seek innovative solutions to this problem.

Today, the sphere of cashless payments is based on the use of bank cards, which have recently come a long way in the field of information protection and, accordingly, cash. A transition to chip cards with increased degrees of protection was made, but not all this allowed for a sharp decrease in the volume of stolen funds from cards. Therefore, today one of the possible directions of the development of the system of cashless payments is a complete refusal from using bank cards and the transition to biometric data of customers, for the recognition of which artificial intelligence systems are used. Among Russian banks, Sberbank is working in this direction, which takes biometric indicators of its customers to create an information base.

One of the main problems in the implementation of innovations is the assessment of their economic efficiency, which allows assessing the degree of readiness of technologies for implementation in practical terms. When innovative information projects are implemented, the main task is the difficulty of evaluating the result that can be obtained from the implementation of the information system. Therefore, research in this direction is relevant and important, both in theoretical and practical aspects.

\section{Key research findings}

\subsection{Definition and types of artificial intelligence}

Recently, artificial intelligence has become very popular. Intelligence includes logic, selfawareness, learning, emotional cognition, creativity and the ability to solve various kinds of problems. It is characteristic of both humans and animals. From an early age, we study the world around us; throughout our lives, we learn the necessary skills by trial and error and gain experience. This is natural intelligence.

When we talk about artificial intelligence, we mean a "smart" system created by a person that is trained using algorithms. His work is based on the same methods: research, training, analysis, etc.

In 1956, the first-ever conference on the subject of artificial intelligence was held, in which scientists from leading US universities and specialists from IBM took part. The event was of great importance in the formation of new science and marked the beginning of major research in this area. [1,2]

For many years, artificial intelligence technologies were not used and were in the experimental stage. Only in the last two decades, these technologies began to receive practical use. This was facilitated by the advent of faster computers, the rapid development of machine learning technologies and big data. The use of artificial neural networks has simplified the implementation of tasks such as video processing, text analysis, speech recognition, and existing methods for solving problems are improved every year.

Today, there are a large number of definitions of artificial intelligence.

In a broad sense, artificial intelligence is the science and technology of creating intelligent machines, especially intelligent computer programs. Artificial intelligence is associated with a similar task of using computers to understand human intelligence but is not necessarily limited to biologically plausible methods.

From the standpoint of the information approach, artificial intelligence is an area of computer science that is engaged in the development of intelligent computer systems, that is, 
systems that have the capabilities that we traditionally associate with the human mind language understanding, learning, reasoning ability, problem solving, etc.

The main properties of AI are language comprehension, learning, and the ability to think and, importantly, act.

In general, there are three types of artificial intelligence. [3]

1. The first type is narrowly targeted, capable of performing only several certain functions. For example, these are electronic assistants, car parking robots, or chess games.

2. The second type is general AI. It is closest to the human. These primarily humanoid robots are as similar as possible to us. They can play the role of the receptionist in hotels, consultants in stores, lifeguards. They can be taught to imitate human emotions to make interaction with a person more constructive.

3. The third kind is the superintelligence. The capabilities of such an intellect will far exceed human ones. Most likely, such "highly intelligent" devices are supposed to unite in a powerful computer network.

\subsection{Analysis of the global market for artificial intelligence in the financial sector}

Today using artificial intelligence technologies has moved from the field of experimental development to the practical plane; so many investors are willing to invest in the development of neural network technologies in the hope of receiving good dividends in the future.

Today's global artificial intelligence market is growing at a very fast pace; the market volume is expected to reach $\$ 52.5$ billion by 2022 (Fig. 1). [4].

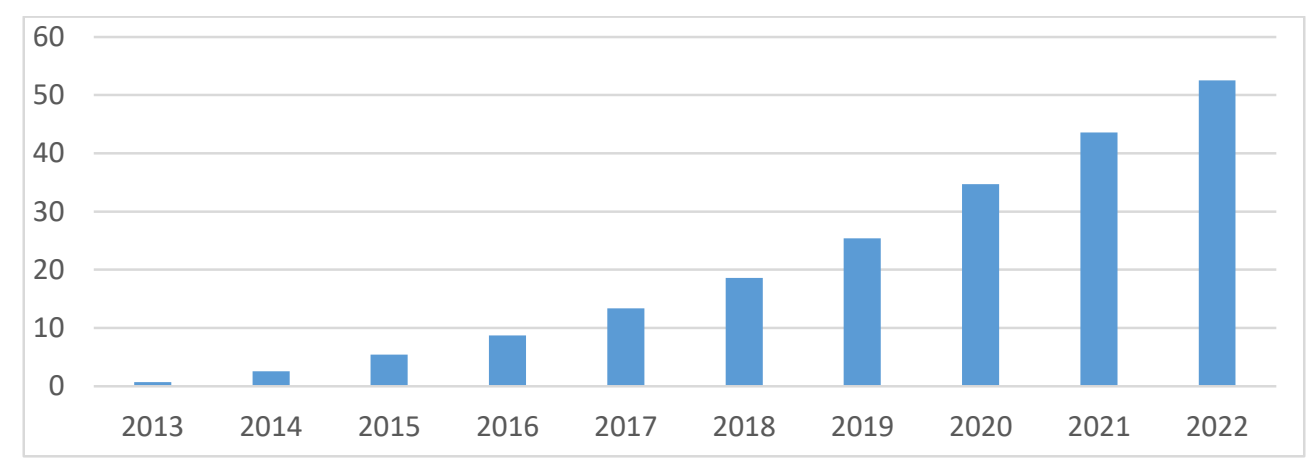

Fig. 1. Dynamics of the global market for artificial intelligence, billions of dollars.

The absolute leader in the market of artificial intelligence technologies is the United States, which occupy over $35 \%$ of the global market (Fig. 2). [5, 6]

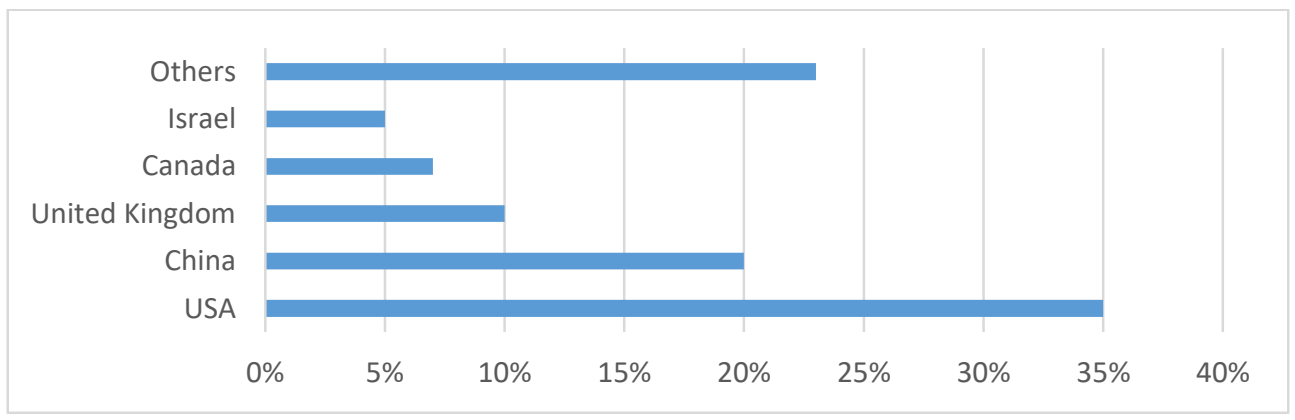


Fig. 2. Countries - leaders in the global market for artificial intelligence, percent.

Recently, China has begun to invest in the development of artificial intelligence technologies at a very fast pace, which, with continued dynamics, can soon overtake the United States.

One of the drivers for the development of neural network technologies is the financial sector. Financial institutions invest heavily in the research and development of these technologies, trying to find a practical use for them.

The volume of the global market for artificial intelligence technologies in the financial sector amounted to about $40 \%$ of the entire world market in 2018. Banks earned about $\$$ 41.1 billion using artificial intelligence in 2018 . This amount includes both direct revenues from the introduction of such technologies, and the volume of reduced costs, and the benefit of improving the efficiency of financial institutions (compared with if they left the same processes and infrastructure) (Fig. 3). [7]

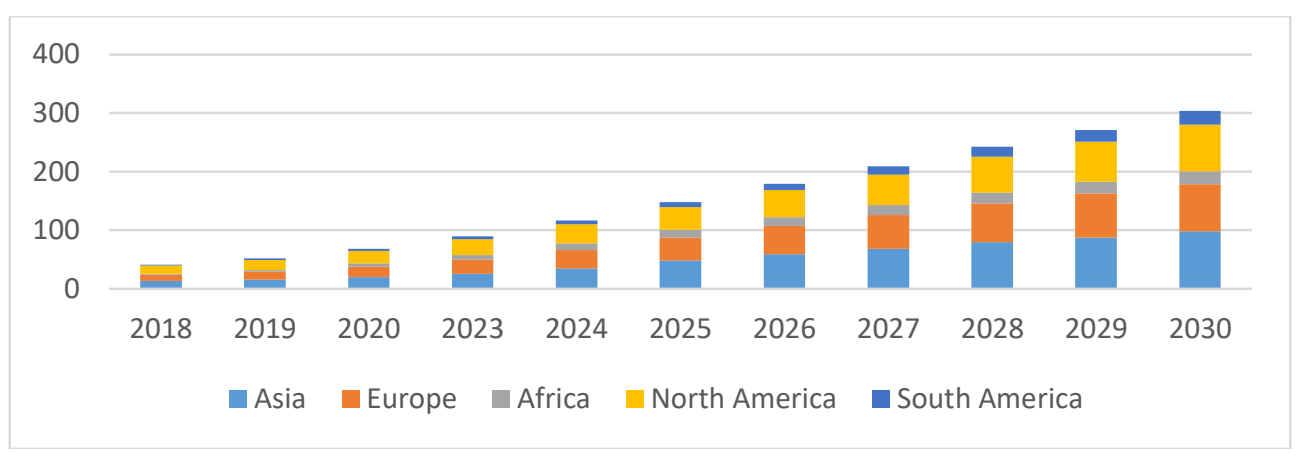

Fig. 3. Forecast of profit dynamics of financial institutions from the introduction of artificial intelligence technologies, billions of dollars.

By 2030, commercial AI projects would bring financial institutions a total of over $\$ 300$ billion.

North America remains the largest market for AI solutions in the banking sector: banks earned \$ 14.7 billion on such technologies at the end of 2018. By 2030, the economic effect of introducing artificial intelligence in the region is expected to jump to $\$ 79$ billion.

However, the Asia-Pacific region can become a leader by 2024, where banks earn and save about 34.6 billion dollars thanks to AI against 11.5 billion dollars in 2018. By 2030, the figure may rise to 98.6 billion dollars, largely due to demand in countries such as China (including Hong Kong), Japan, South Korea, and Singapore.

The main area of development of artificial intelligence technologies in the financial sector will be the area of interaction with customers (Fig. 4). [8]

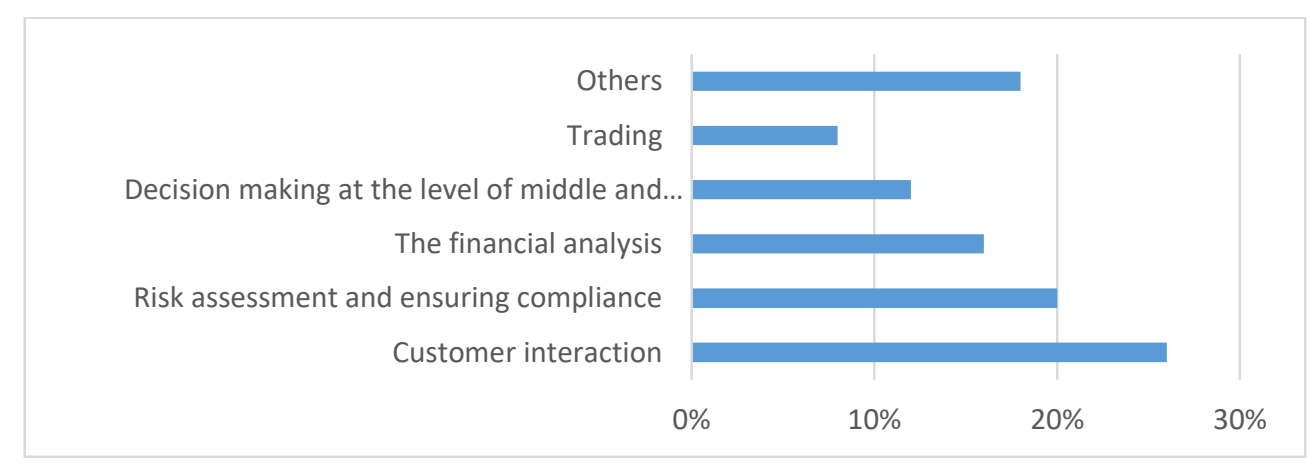


Fig. 4. Areas of banking intelligence in financial institutions, percent.

For example, robo advising has become an alternative to financial advisers on banking, specific purchases, and other cash transactions online. Robo-advisors provide great advantages in the field of online trading. First of all, these are using in one action and opening an account in real-time, monitoring, current news, and processing of large volumes of transactions immediately. Distribution of brokers on social networks makes investment knowledge more accessible and understandable, and communication with a client is simple and targeted.

According to forecasts, the volume of asset management under the control of roboadvisers in the US is expected to reach $\$ 2.2$ trillion by 2020 .

\subsection{Analysis of the economic efficiency of neural network technologies in cashless payments}

Artificial intelligence is revolutionizing the banking sector by identifying fraud in financial transactions based on a predetermined set of rules. Besides, one of the promising areas in the field of artificial intelligence in the financial sector is the ability to use these technologies in a cashless payment system, switching to biometric parameters of clients, which allow to completely abandon bank cards.

One of the main tasks in the implementation of innovative information systems is the assessment of their economic efficiency. When introducing innovative projects, the economic benefit is often not obvious, because when introducing new information systems, many uncertainties make it impossible to obtain a sufficiently clear algorithm for calculating the economic effect.

Today there are three large groups of methods for assessing the economic efficiency of an information investment project.

The first group of methods is financial or quantitative methods for determining the economic efficiency of the implementation of an IT project, these methods are based on economic calculations basing on financial or any quantitative indicators that allow estimating the economic benefits of the project to one degree or another.

The second group of methods is qualitative methods, the main idea of which is to determine the goals, priorities, and indicators for them, based on which one can conduct a comparative analysis according to the specified criteria and choose the best option among the proposed ones. Some methods often act, as an additional mechanism to financial methods when monetary indicators alone are not enough and one need to determine the best option for additional values.

The third group of methods is probabilistic methods that are used in situations of insufficient certainty, that is, in those cases when it is difficult or even impossible to obtain clear quantitative indicators. In this case, they begin to track the probabilistic indicators that can be obtained under certain conditions, after which, they evaluate the economic efficiency of the IT project with a certain degree of probability. These methods are among the youngest ones and require rather cumbersome calculations to obtain the necessary indicators.

In our case, the economic effect of introducing an artificial intelligence system is obvious - this is a decrease in the volume of stolen funds in the cashless payments system of individuals.

A model of net present value is constructed related to the group of financial methods for assessing the economic efficiency of an information project.

The main indicator of the effectiveness of an information investment project is NPV - the net present value of the project, which is calculated using the following formula: 
where

$$
N P V=\sum_{t=0}^{T} \frac{C F_{t}}{\prod_{i=0}^{t}\left(1+r_{i}\right)}-\sum_{t=0}^{t} \frac{I_{t}}{\prod_{i=0}^{t}\left(1+r_{i}\right)}=\sum_{t=0}^{T} \frac{N C F_{t}}{\prod_{i=0}^{t}\left(1+r_{i}\right)}
$$

$\mathrm{T}$ is the number of planned periods for the implementation of the information project, $\mathrm{NCF}$ is the net cash flow at time $\mathrm{t}$, $\mathrm{r}$ is the discount rate.

NPV for the implementation of the investment project of the artificial intelligence system can be determined by the following formula:

where

$$
N P V=\sum_{t=0}^{T} \frac{N C F_{t c b}}{\prod_{i=0}^{t}\left(1+r_{i}\right)}
$$

$\mathrm{NCF}_{\text {tdb }}$ is the net cash flow for an information system in a financial institution at time $t$.

The calculation of the total cost of the information project can be estimated by the following formula:

where

$$
E=K+C * n,
$$

$\mathrm{K}$ is the capital (one-time) costs, which are determined at the beginning of the launch of the investment project;

$\mathrm{C}$ is the operating costs, which are determined for the normal functioning of the information system, taking into account discounting over time;

$\mathrm{n}$ is the number of years, for which the investment project is designed.

To build a model, let us consider the construction of an information system for one million customers of a financial institution, which is the base indicator for evaluating the effectiveness of the system with a larger number of customers.

Depending on the increase in the number of bank customers, the cost of designing and implementing an artificial intelligence information system also increases. This is also due to an increase in the design time of the system itself, the volume of entering customer information into the system, as well as an increase in the cost of the information project infrastructure. An approximate dependence of the cost of the information system on the number of bank customers is presented in Figure 5. [9]

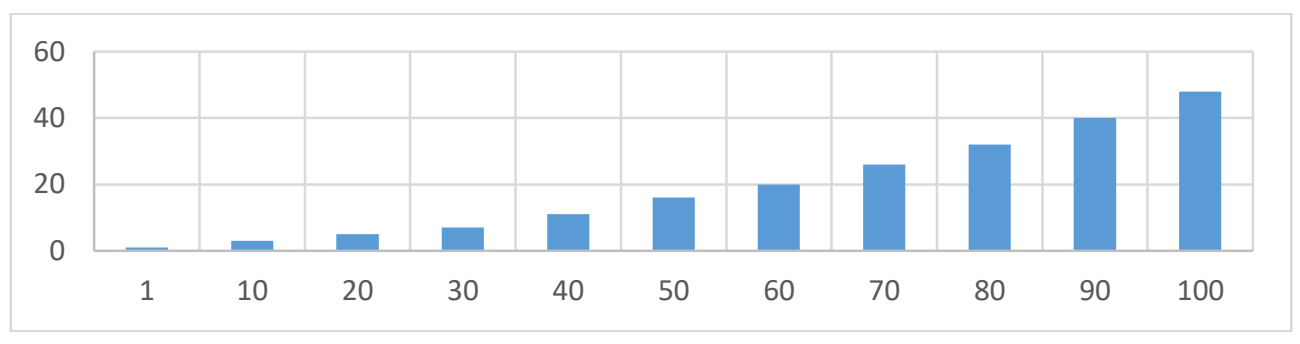

Fig. 5. Dependence of the cost of an information system on the number of clients of a financial institution, in units of the cost of a basic information system.

The cost of commercial AI projects depends on many factors - the purpose of development, scale, industry, country, team composition, marketing, etc. Therefore, it is impossible to say exactly how much it will cost to develop and launch a specific project without knowing such factors. However, one can use the statistics of completed IOC to look at industry averages and extrapolate them to similar projects. Therefore, according to CoinDesk statistics, the average ICO amounted to 51 million dollars in 2018, which is almost two times more than in 2017. Fabric Ventures report gives similar figures: \$ 50 million. The distribution of projects by volume is shown in Figure 6. [10] 


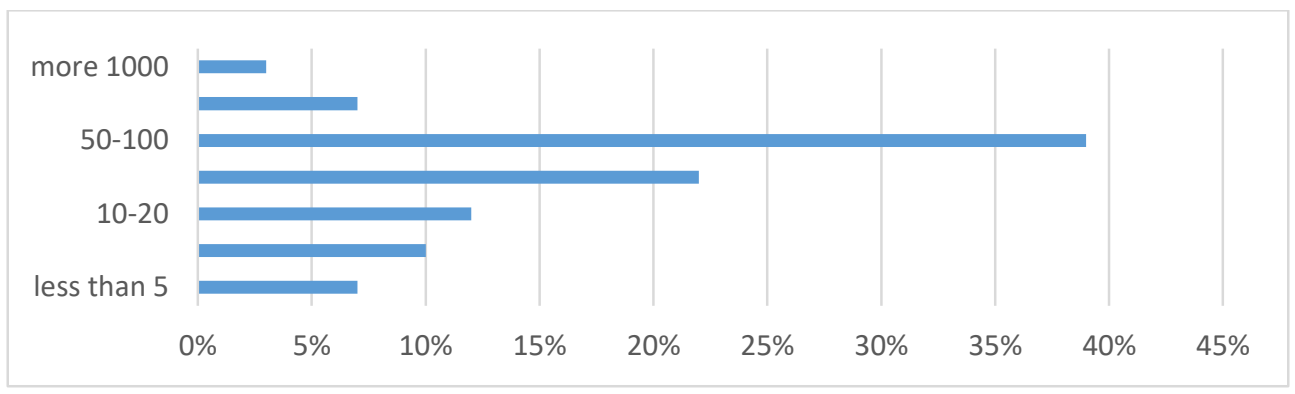

Fig. 6. Distribution of large projects in the field of artificial intelligence by cost, percent

Fifty million dollars is the average for all projects. If we consider the median value, discarding the largest projects, the value will be about 24-25 million dollars.

The cost of large projects is very much dependent on the industry, in which they are implemented. In the financial sector, the average cost of projects with artificial intelligence averaged about 84 million dollars.

Depending on the complexity of the project, the time for its development and implementation can vary from several months to several years (Fig. 7). [11]

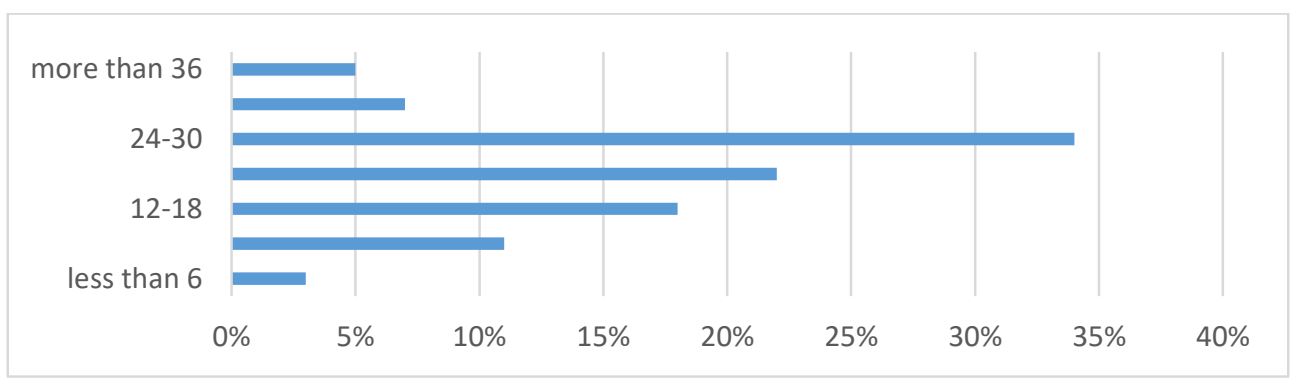

Fig. 7. Distribution of AI projects depending on the number of months per project, percent

The median value is twenty-six months per project.

The number of developers can vary greatly from a few specialists to a team of several dozen people. On average, the number of developers varies from 10 to 20 people, depending on its complexity.

The average salary of developers of projects for the introduction of systems with artificial intelligence is about 180 thousand dollars a year (Fig. 8). [12]

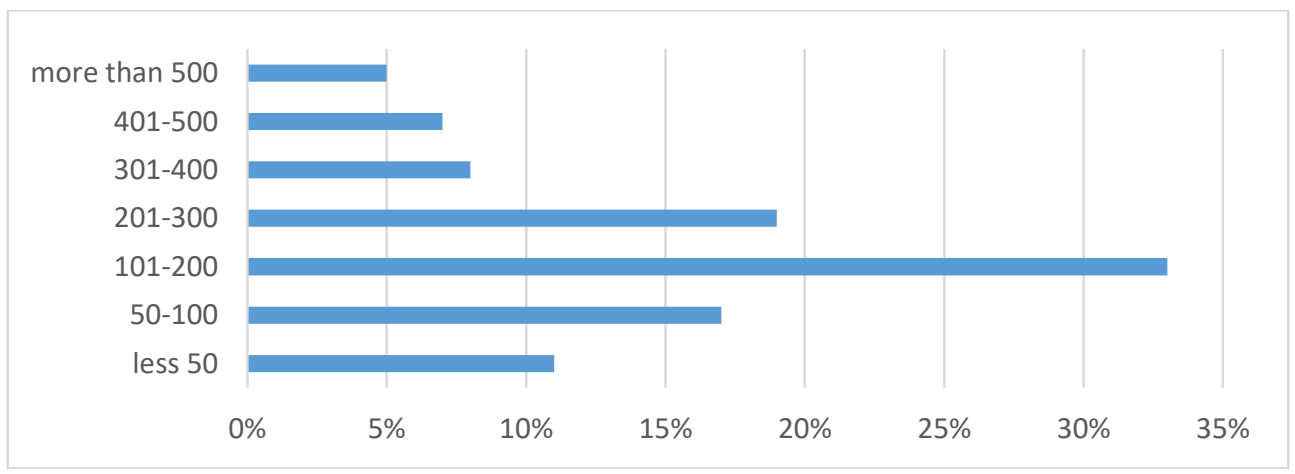

Fig. 8. Distribution of the average annual salary of AI project developers, percent 
Usually, when innovative information projects are used, operating costs can vary greatly, and very often, they are estimated depending on one-time costs (Fig. 9). [13, 14]

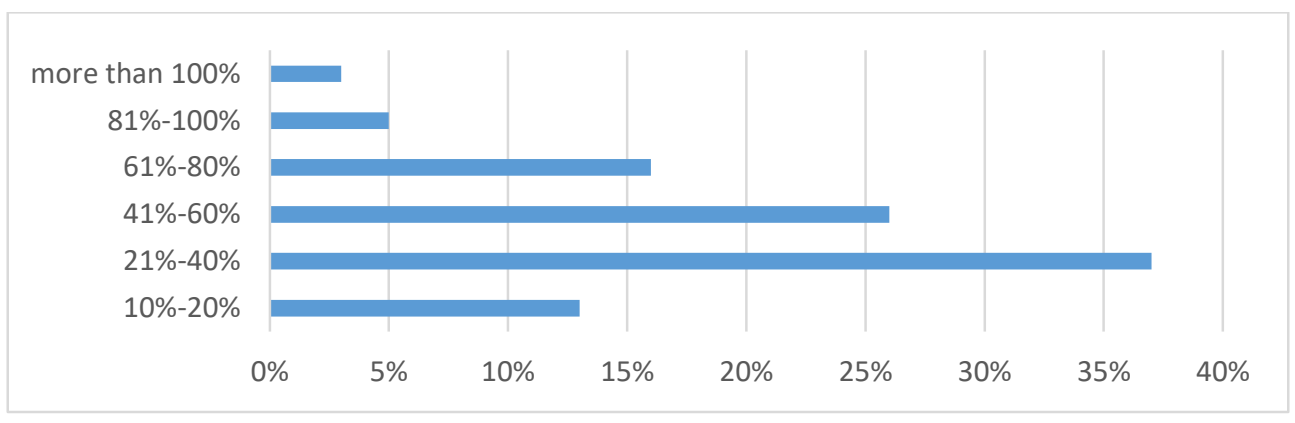

Fig. 9. Distribution of operating costs, depending on one-time costs, percent

The average value of the operating costs of the volume of one-time costs is about $49 \%$.

The main problem in the implementation and use of an innovative information system is the determination of the economic result of its functioning. A reduction for money that the bank loses in fraudulent transactions will be a result for this project.

This indicator can be obtained from the following considerations. First, we find the specific value of the amount of cash per one client of the bank in fraudulent transactions, which can be estimated on the basis of the following formula:

where

$$
q_{\mathrm{c}}=N_{\text {all }} / Q_{\text {all }}
$$

$\mathrm{q}_{\mathrm{c}}$ is the specific amount of money per client worldwide stolen as a result of fraudulent transactions;

$\mathrm{N}_{\text {all }}$ is the number of all banks customers in the world;

$\mathrm{Q}_{\text {all }}$ is the amounts of stolen funds during operations.

For each financial institution, the amount of cash can be estimated using the following formula:

$$
Q_{b}=q_{c} * N_{b}
$$

where

$\mathrm{Qb}$ - the amount of money stolen because of fraudulent transactions in a particular financial institution;

$\mathrm{Nb}$ - number of clients of a particular financial institution.

Based on formula (4), formula (5) can be represented as follows:

$$
Q_{b}=N_{\text {all }} / Q_{\text {all }} * N_{b}
$$

When an information system with artificial intelligence technologies is implemented, the volume of funds stolen can be reduced by $60-80 \%$, and then the volume of funds saved during the implementation of a decentralized database will be as follows:

where

$$
Q_{b s}=Q_{b} * k=N_{\text {all }} / Q_{\text {all }} * N_{b} * k
$$

$\mathrm{k}$ is the correction factor showing how much of the possible stolen funds remain in a financial institution.

The amount of money stolen in non-cash payment systems is determined in the range of \$15-20 billion annually worldwide.

Let us carry out modeling for three different options, with the most favorable economic indicators, average indicators and the most unprofitable ones from an economic point of view. The planning horizon is taken in ten years. 
In the first scenario, the dependence of NPV on the number of clients of a financial institution is shown in Figure 10.

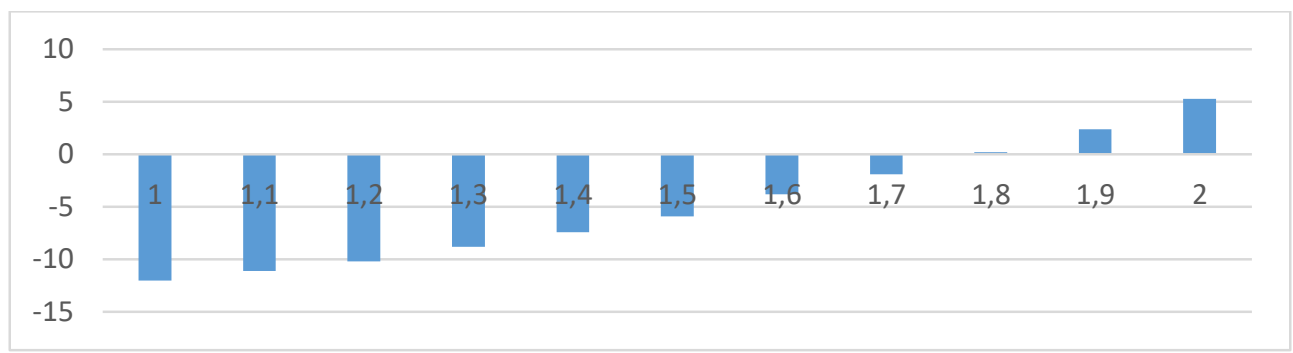

Fig. 10. NPV dependence on the number of clients of a financial institution with minimum model values, millions of people

The simulation results at average values are presented in Figure 11.

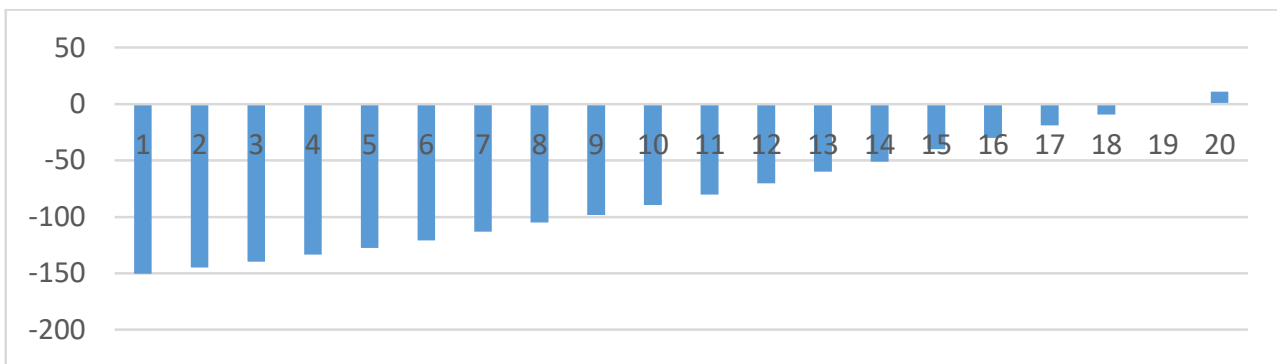

Fig. 11. NPV dependence on the number of clients of a financial institution with median model indicators, millions of people

The modeling results at the maximum possible ineffective indicators are presented in Figure 12.

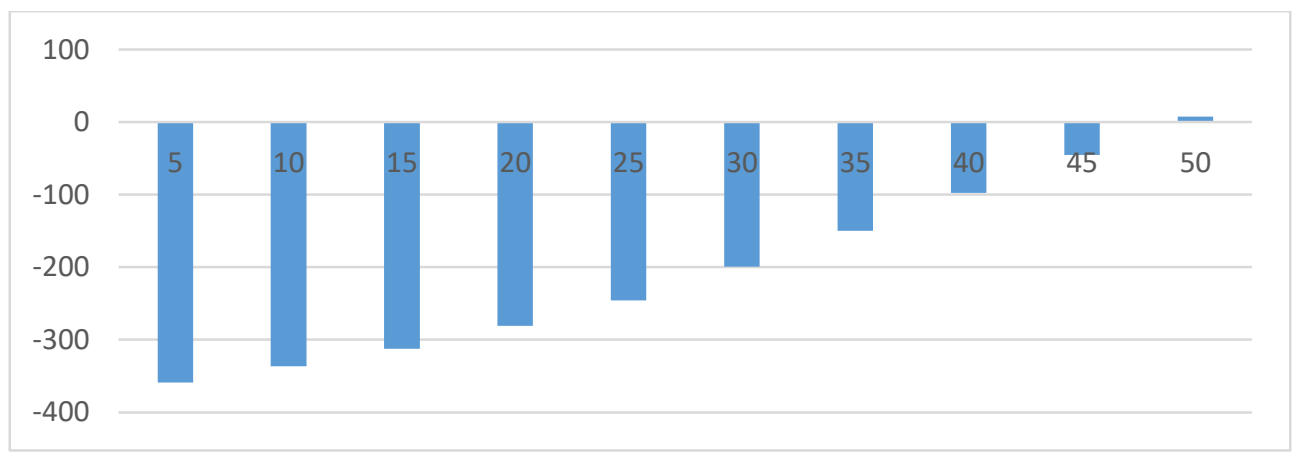

Fig. 12. NPV dependence on the number of clients of a financial institution with the highest possible model indicators, millions of people

\section{Conclusion}

In the modern world, there is a large-scale introduction of information and communication technologies that have led to the digital transformation of the global economy. Modern innovative digital technologies have been developed and applied in all areas of economic 
development. Completely new forms of economic development have appeared in many traditional sectors, for example, Fintech in the financial sector;

Today, one of the most promising innovative technologies is artificial intelligence technology, whose global market is expected to reach $\$ 52.5$ billion by 2022 . One of the leaders in the artificial intelligence market is financial institutions, which earned more than $\$ 41.1$ billion in 2018 by using these technologies, and this figure is expected to grow to $\$$ 300 billion by 2030 ;

Today there are quite a few areas in the banking sector where the use of artificial intelligence is possible; one of such promising areas is cashless payments, where the amount of stolen funds worldwide is about 15-20 billion dollars annually;

One of the main tasks in implementing innovative systems is to assess their economic efficiency. Based on the constructed model of net present value, an analysis of investment projects depending on the size of the client base of a financial institution was carried out. It showed that the introduction and use of the artificial intelligence system at the most favorable economic indicators, expressed as the minimum cost of the system, operating costs, the economic effect will be manifested if the number of bank customers exceeds 1.8 million people, this figure will be about 19 million customers with average indicators, and at the most unfavorable indicators, the economic effect cannot be achieved. Therefore, the boundary possible values were determined at which the volume of the customer base should exceed 48 million people;

The simulation showed that the introduction of such systems is the prerogative of the largest financial institutions because systems with artificial intelligence require high costs of implementation and operation. Therefore, today, most credit organizations take a wait and see attitude on this issue.

\section{References}

1. O. V., Bukunova, and A. S. Bukunov. Tools of Data Transmission at Building Information Modeling, 2019

2. A. Levina, Operational and Information Technologies within the Enterprise Architecture: Mining Industry Case, vol. 1259 AISC, 2021

3. Z. Li, et al. Management and Practice of International Science and Technology Innovation Cooperation Driven by Big Data, 2021, doi:10.1109/CSEI51395.2021.9477741

4. Mikheev, V., Grechnikova, A., Agafonova, D., \& Klochkov, Y. (2019). Data management for solving the problem of sequential shaping simulation. Paper presented at the IOP Conference Series: Materials Science and Engineering, , 618(1) doi:10.1088/1757-899X/618/1/012084

5. M. Afzal, M. T. Shafiq, and H. Al Jassmi. "Improving Construction Safety with Virtual-Design Construction Technologies - A Review." Journal of Information Technology in Construction, vol. 26, 2021, pp. 319-340, doi:10.36680/j.itcon.2021.018

6. J. N. Angelis, and J. C. Miller. "An Empirical Investigation of the Effects of Individuality on Responses to Data Theft Crimes." IEEE Transactions on Engineering Management, vol. 68, no. 6, 2021, pp. 1663-1676, doi:10.1109/TEM.2020.2974742

7. V. L. Badenko, et al. "Integration of Digital Twin and BIM Technologies within Factories of the Future." Magazine of Civil Engineering, vol. 101, no. 1, 2021

8. G. M. Begany, and J. R. Gil-Garcia. "Understanding the Actual use of Open Data: Levels of Engagement and how they are Related." Telematics and Informatics, vol. 63, 2021, doi:10.1016/j.tele.2021.101673 
9. V. V. Pshenichnikov, V. E. Krolivetskaya, and A. V. Babkin. Bank Running Model's Evolution on the Wave of Information and Communication Technology Development, 2018.

10. B. H. Hassan, et al. Performance Assessment of State Estimation in Cyber-Physical Energy Systems, 2021, doi:10.1109/PowerTech46648.2021.9494760

11. J. M. Haut, et al. "Distributed Deep Learning for Remote Sensing Data Interpretation." Proceedings of the IEEE, vol. 109, no. 8, 2021, pp. 1320-1349, doi:10.1109/JPROC.2021.3063258

12. K. Kaur, G. Kaddoum, and S. Zeadally. "Blockchain-Based Cyber-Physical Security for Electrical Vehicle Aided Smart Grid Ecosystem." IEEE Transactions on Intelligent Transportation Systems, vol. 22, no. 8, 2021, pp. 5178-5189, doi:10.1109/TITS.2021.3068092

13. C. Zhang, and Y. Lu. "Study on Blockchain Technology from an Information System Perspective." High Technology Letters, vol. 27, no. 2, 2021, pp. 146-152, doi:10.3772/j.issn.1006-6748.2021.02.005

14. F. Yao, and Y. Wang. Financial Innovation System of Commercial Banks Based on Big Data Technology, 2021, doi:10.1109/ICSGEA53208.2021.00074 